\title{
Loggerhead turtle by-catch depends on distance to the coast, independent of fishing effort: implications for conservation and fisheries management
}

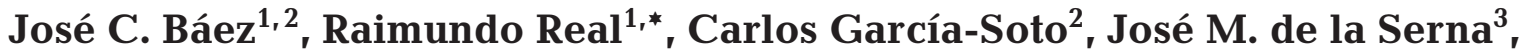 \\ David Macías $^{1,3}$, Juan A. Camiñas ${ }^{3}$ \\ ${ }^{1}$ Department of Animal Biology, University of Malaga, 29071 Malaga, Spain \\ ${ }^{2}$ Spanish Oceanographic Institute, Oceanographic Centre of Santander, Promontorio de San Martín s/n, \\ 39004 Santander, Spain \\ ${ }^{3}$ Spanish Oceanographic Institute, Oceanographic Centre of Malaga, Puerto Pesquero s/n Apdo. 285, 29640 Fuengirola, \\ Malaga, Spain
}

\begin{abstract}
Drifting longline is considered one of the most dangerous fishing gears for marine turtles and is their principal threat in the western Mediterranean Sea. During the summers of 2000 to 2003, 179 fishing operations were observed onboard a traditional Spanish drifting longline boat in the Balearic Sea (western Mediterranean) to analyse the effects of fishing effort and ecogeographical factors on the by-catch of loggerhead turtles Caretta caretta. We observed 4074 swordfish captured and 675 loggerhead turtles by-caught. The probability of catching at least 1 loggerhead was related to the distance of the fishing-ground to the coast and, to a lesser extent, depth, both independent of fishing effort. The average number of loggerheads captured was spatially structured only according to mean distance to the coast. However, the number of swordfish captured was correlated with fishing effort but was not correlated with distance to the coast or depth. Distance to the coast was correlated with gear retrieval time, sea surface temperature and velocity, and phytoplankton concentration. As the number of loggerheads captured was independent of the number of hooks, the number of fishing operations was a better unit than the number of hooks to assess loggerhead by-catch. Limiting drifting longline fishing activity to within 35 international nautical miles from the coast could reduce loggerhead by-catch substantially without affecting swordfish captures and with little resistance from fishermen.
\end{abstract}

KEY WORDS: By-catch $\cdot$ Drifting longline $\cdot$ Sea turtle $\cdot$ Loggerhead $\cdot$ Caretta caretta $\cdot$ South-western Mediterranean $\cdot$ Swordfish fishery

\section{INTRODUCTION}

Three of the 7 species of sea turtle are considered critically endangered and 3 others are endangered (IUCN 2004), partly because of fisheries' by-catch and other anthropogenic causes (FAO 2004). For this reason, there is increasing global interest in the study of incidental catch and mortality of sea turtles associated with different fisheries, e.g. artisanal (Báez et al. 2006), coastal seiner (e.g. Cheng \& Chen 1997), dredge (Mur- ray 2004), driftnet (e.g. Silvani et al. 1999), gillnet (e.g. Julian \& Beeson 1998), trawl (e.g. Robins 1995), and drifting longline (e.g. Witzell 1999, Chaloupka et al. 2004, Ward et al. 2004, Carranza et al. 2006).

The incidental catch of sea turtles in drifting longline fisheries has gained recent international attention (FAO 2004, Lewison et al. 2004, Gilman et al. 2006). This gear is used to fish different species, mainly albacore Thunnus alalunga, bigeye tuna T. obesus, bluefin tuna T. thynnus, swordfish Xiphias gladius, yellowfin 
tuna T. albacares, and different species of shark, and is considered an important threat for the loggerhead sea turtle Caretta caretta (Lewison et al. 2004, Camiñas et al. 2006), an endangered species. Drifting longline is also considered a significant threat for the loggerhead turtle in the Mediterranean Sea, with more than 60000 ind. estimated to be caught annually (Laurent et al. 2001, Lewison et al. 2004). The Spanish fleet performs an important fishing activity in this area; Laurent et al. (2001) estimated that 20000 ind. are caught annually by the Spanish fleet, which represents $10 \%$ of the worldwide loggerhead captures estimated by Lewison et al. (2004).

Studies on loggerhead by-catch in longline fisheries have mainly focused on differences associated with different boat characteristics and gear type (Camiñas et al. 2006), the use of 2 different baits, namely chub mackerel Scomber japonicus and squid Illex sp., and different hook types (e.g. Swimmer et al. 2005, Watson et al. 2005). Some of these studies recommended the use of chub mackerel and circular hooks, which is not accepted by Spanish fishermen (Báez et al. 2006), as their use is considered to diminish yields of target species (Gilman et al. 2006). Other recommendations for reducing sea turtle by-catch were: (1) setting gear below depths at which turtles are abundant, (2) using single-hook fish bait instead of multiple-hook threading, (3) reducing gear soak time and retrieval during the daytime, and (4) avoiding by-catch hotspots (Gilman et al. 2006). Recommendations (2) and (3) are traditionally followed by the Spanish longline fleet. However, this fleet uses a surface drifting longline, contravening recommendation (1), and operates in a by-catch hotspot, the Balearic Sea.

Although studying commercial fishing operations is important to assess the relationship between economic profit and conservation proposals, this approach has been little explored. In this context, the Spanish Institute of Oceanography (IEO) put into practice an onboard observer program to collect direct information

Table 1. The principal technical characteristics of the observation boat compared to the Carboneras and Spanish fleets during the study period. GRT, gross registered tons; brackets, range. Data set available from www.mapa.es/es/pesca/pags/ flota/censo.htm

\begin{tabular}{|lccc|}
\hline & Number & $\begin{array}{c}\text { Mean length } \\
(\mathrm{m})\end{array}$ & Mean GRT \\
\hline Observation boat & 1 & 23.62 & 52.24 \\
Carboneras fleet & 40 & 20 & 40 \\
& & $(13-27)$ & $(9-90)$ \\
Mediterranean & 105 & 17 & 30 \\
Spanish fleet & & $(9.5-27)$ & $(3-90)$ \\
\hline
\end{tabular}

about target and incidental species captured in commercial longline fisheries.

In the present study, we used data recorded in the above-mentioned program to analyse the effects of different fishing strategies on loggerhead turtle by-catch under a variety of ecological conditions. The ultimate aim was to explore alternative fishing practices that are easily acceptable to Spanish fishermen and conducive to reducing loggerhead by-catch in the Spanish surface longline fleet.

\section{MATERIALS AND METHODS}

The Spanish drifting longline fleet based in Mediterranean ports consists of 105 vessels that target mainly swordfish throughout the year. The fishing grounds involve a large area of the western Mediterranean basin, between $36^{\circ}$ and $44^{\circ} \mathrm{N}$ and $02^{\circ} \mathrm{W}$ and $05^{\circ} \mathrm{E}$, and include 3 different fishing areas: (1) Alboran Sea, used by approximately $5 \%$ of the operative fleet, (2) southwestern Mediterranean Sea (primarily around the Balearic Islands and in the Ibiza Channel), used by approximately $80 \%$ of the operative fleet and (3) north-western Mediterranean Sea (primarily the Ebro Basin), where approximately $15 \%$ of the fleet operates.

Observations were carried out from a commercial traditional Spanish drifting longline fishing boat, which was considered to be representative of the Spanish fleet targeting swordfish throughout the year in the south-western Mediterranean Sea (see Fig. 1). The boat was selected at random among the vessels with these characteristics based in Carboneras Port (Almería, southern Spain), where $50 \%$ of the Spanish drifting longline vessels that work in the south-western Mediterranean are based. The technical characteristics of the boat are summarised in Table 1. We restricted observations to a single boat, because turtle catch rates can be tied to individual fishing vessels and/or captains, due to individual variability in fishing behaviour. Therefore, it is advisable to eliminate this variable so that the effect of other factors may be more effectively investigated. If a bias in favour or against turtle by-catch is associated with this particular vessel or captain, it will be constant throughout all fishing operations and cannot be the cause of any relationship between turtle by-catch and the analysed variables. The same observer collected the data to prevent the influence of different observation behaviours from obscuring the results; thus, if an observation bias existed, it was constant throughout the study.

The fishing gear consisted of a traditional Spanish style monofilament polyamide longline. This is surface gear, although actual fishing depth depends on the 


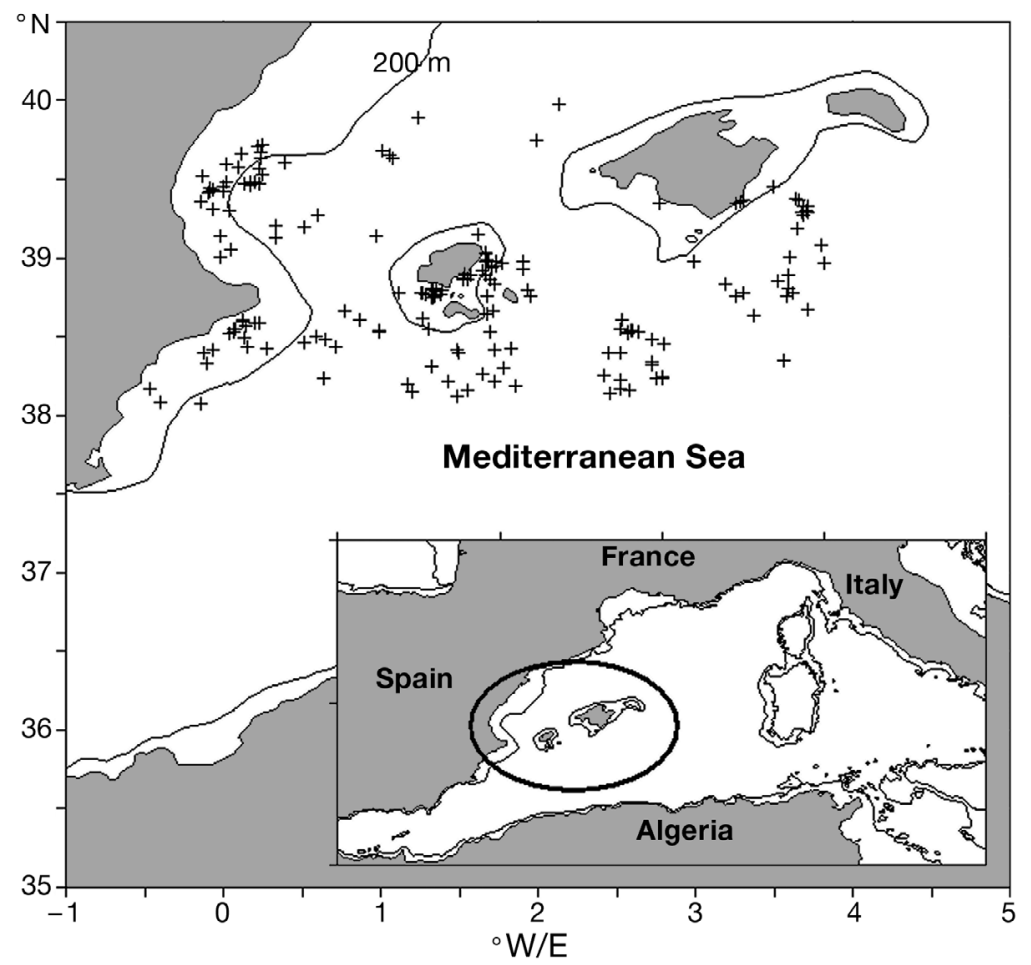

Fig. 1. Locations of the observed fishing operations; $200 \mathrm{~m}$ depth contour is indicated

number of floats. The hooks were ' $J$ '-shaped Mustad no. 1 ( $7 \mathrm{~cm}$ in length and $3.5 \mathrm{~cm}$ wide) and were baited mainly with Argentine squid and chub mackerel (see Laurent et al. 2001 for a detailed description).

Observations were made during 2000 to 2003 from July to September, when adult and juvenile loggerhead turtles concentrate in the Balearic Sea and swordfish fishing activity increases (Laurent et al. 2001). We observed 179 fishing operations onboard in this fishing area (Fig. 1).

The capture per unit effort (CPUE) was measured using the traditional index R (no. incidental catches/no. hooks ${ }^{3}$; Yeung 1999, Laurent et al. 2001, Lewison et al. 2004) and the new index F (no. incidental catches/no. fishing operations; Camiñas et al. 2006). In index F, a fishing operation refers to all procedures performed between deploying a longline set and retrieving all of the gear, which is usually carried out in $<20 \mathrm{~h}$ on average.

For every fishing operation, we recorded the number of hooks and the time that the hooks remained in the water (soak time), which we considered to be technical variables related to fishing effort. We also recorded the mean value between the nearest distance to the coast at the beginning and the end of the longline lowering (distance to the coast), and the mean value between the depth at the beginning and the end of each longline set (fishing-ground depth), which we considered to be ecogeographical variables. Ecogeographical variables are quantitative geographical features that could be related to ecological or human-related characteristics of each fishing ground (Hirzel et al. 2002). Distance to the coast was measured in international nautical miles (nm), where $1 \mathrm{~nm}=1852 \mathrm{~m}$. We preferred $\mathrm{nm}$ because this unit is more commonly used in the fisheries context. Covariations between those variables and the indices $\mathrm{F}$ and $\mathrm{R}$ applied to the loggerhead and the swordfish were tested using Kendall's rank correlation coefficient $\tau_{\mathrm{b}}$.

We performed univariate logistic regression of the presence or absence of loggerhead by-catch for each unit effort (i.e. each fishing operation and each 1000 hooks) on the above mentioned variables separately to test the predictive capacity of each variable. We also performed multiple stepwise logistic regression of the presence or absence of loggerhead by-catch on the predictive variables together to test if the probability of incidentally catching loggerheads (1 or more) per unit effort may be predicted by the combination of several ecogeographical and technical factors.

Logistic regression has been used by Ward et al. (2004) to assess the effect of different factors on the probability of catching an animal when fishing with longline sets. The logistic regression model has the form:

$$
\mathrm{p}=\frac{\mathrm{e}^{y}}{1+\mathrm{e}^{y}}
$$

where $\mathrm{p}$ is the probability of an event occurring (in this case the probability of catching at least 1 loggerhead in 1 longline set or in 1000 hooks), e is the basis of the natural logarithm and $y$ is a regression equation in the form:

$$
y=a+b x_{1}+c x_{2}+\ldots+n x_{n}
$$

where $x_{1}$ is a selection of the variables used (see Hosmer \& Lemeshow 2000, for a detailed description). We tested the logistic models with a $\chi^{2}$-test of goodness of fit. The parameters (e.g. $a, b$ ) in Eq. (2) were estimated by maximum likelihood and tested with Wald's test.

We divided each significant predictive variable into 15 classes of equal range and analysed the proportion of unit efforts with at least 1 loggerhead caught and the average loggerhead $\mathrm{F}$ and $\mathrm{R}$ indices in each class. We grouped the classes according to the Euclidean distance among CPUE values using a cluster analysis, to detect groups of contiguous classes with similar values of CPUE. We tested differences of CPUE among these different groups of classes using the KruskalWallis test. 
We used Kendall's $\tau_{\mathrm{b}}$ coefficient to correlate each significant predictive variable with the available satellite measurements of sea surface temperature $\left({ }^{\circ} \mathrm{C}\right.$, daily values available for 71 fishing points) collected by the AVHRR thermal infra-red sensor, sea surface velocity $\left(\mathrm{m} \mathrm{s}^{-1}\right.$, daily values with each daily observation averaging the 10 previous days) measured by the satellites JASON-1, TOPEX, ERS-2, ENVISAT and GFO, and phytoplankton concentration $\left(\mathrm{mg} \mathrm{m}^{-3}\right.$, weekly values, available for 163 fishing points) taken by the SeaWiFS colour sensor. The data were extracted from the databases of NASA PO-DAAC (Pathfinder version 5), US JGOFS and NOAA. The mean spatial errors were $\sim 0.01^{\circ}, \sim 0.05^{\circ}$ and $\sim 0.25^{\circ}$ of latitude/longitude respectively. We also correlated them with gear retrieval time (available for 126 fishing operations).

\section{RESULTS}

The observed fishing operations involved 3544 fishing hours and 581666 deployed hooks, with 4074 swordfish captured and 675 loggerhead turtles bycaught. We obtained overall CPUE mean values of $\mathrm{F}=$ 3.77 and $\mathrm{R}=1.16$.

The results of performing univariate and stepwise multiple logistic regressions showed that for both unit efforts, the probability of catching at least 1 loggerhead increased significantly with distance to the coast, fishing-ground depth, and the 2 variables together (Table 2). The probability of catching at least 1 loggerhead during a fishing operation increased more logistically in relation to distance to the coast (Fig. 2a) than to fishing-ground depth (Fig. 2b). The same occurred, to a lesser extent, with the probability of catching at least 1 loggerhead in a stretch of 1000 hooks (Fig. 3a, b).

The result of dividing the whole range of distance to the coast into 15 groups yielded classes of $5 \mathrm{~nm}$ each (broadly equivalent to $9250 \mathrm{~m}$ ), while the 15 classes of fishing-ground depth were $120 \mathrm{~m}$ each. The proportion of fishing operations and stretches of 1000 hooks with loggerhead by-catch in each class showed a better fit with the expected probability as a function of distance to the coast (Figs. 2a and 3a) than as a function of fishing-ground depth (Figs. 2b and 3b).

We only obtained contiguous groups of classes according to the similarity of their CPUE values for distance to the coast (see individual values in Figs. 2c and $3 \mathrm{c}$ ), whereas the classes were not spatially structured according to fishing-ground depth (Figs. $2 \mathrm{~d}$ and $3 d)$. The groups included fishing grounds at less than $10 \mathrm{~nm}(18500 \mathrm{~m})$, between 10 and $34.99 \mathrm{~nm}$ (equivalent to $18520 \mathrm{~m}$ and $64801 \mathrm{~m}$ ), and farther than $35 \mathrm{~nm}$ $(64820 \mathrm{~m})$ from the coast. The probability of catching loggerhead during a fishing operation (Fig. 2a) remained stable around 0.17 for the 73 fishing operations performed within $9.99 \mathrm{~nm}$ from the coast and increased sharply between $10 \mathrm{~nm}$ and $34.99 \mathrm{~nm}$ from the coast. In fishing operations performed farther than $35 \mathrm{~nm}$ from the coast, this probability became asymptotic, reaching a value of practically 1 . The differences in the values of $\mathrm{F}$ and $\mathrm{R}$ among these 3 stretches were highly significant (Kruskal-Wallis test using the $\mathrm{F}$ index: $H=80.71, \mathrm{df}=2, \mathrm{p}=2.97 \times 10^{-18}, \mathrm{n}=179$; Kruskal-Wallis test using the R index: $H=81.59, \mathrm{df}=2$, $\mathrm{p}=1.91 \times 10^{-18}, \mathrm{n}=179$ ). Within $10 \mathrm{~nm}$ of the coast, the average by-catch was reduced to 1 loggerhead every 3 fishing operations and every 10000 hooks. Between 10 and $35 \mathrm{~nm}$, an average of 3 loggerheads were by-

Table 2. Caretta caretta. Significant logit functions resulting from multivariate and univariate logistic regression of presence/ absence of loggerhead turtle by-catch in each fishing operation and in each stretch of 1000 hooks on ecological and technical variables. FD, fishing-ground depth; DC, distance to the coast; Cte, constant; $B$, coefficient

\begin{tabular}{|c|c|c|c|c|c|c|}
\hline Presence/absence & Model & Variables & $B$ & Wald test & $\mathrm{df}$ & $\mathrm{p}$ \\
\hline \multirow[t]{7}{*}{ Longline set } & Multivariate & $\mathrm{DC}$ & 0.069 & 8.97 & 1 & 0.0027 \\
\hline & & FD & 0.015 & 4.45 & 1 & 0.035 \\
\hline & & Cte & -2.064 & 40.38 & 1 & $<0.0001$ \\
\hline & Univariate & DC & 0.105 & 38.95 & 1 & $<0.0001$ \\
\hline & & Cte & -2.07 & 40.77 & 1 & $<0.0001$ \\
\hline & Univariate & FD & 0.0019 & 45.603 & 1 & $<0.0001$ \\
\hline & & Cte & -1.58 & 35.92 & 1 & $<0.0001$ \\
\hline \multirow[t]{7}{*}{1000 hooks } & Multivariate & DC & 0.054 & 18.46 & 1 & $<0.0001$ \\
\hline & & $\mathrm{FD}$ & 0.013 & 27.54 & 1 & $<0.0001$ \\
\hline & & Cte & -2.68 & 164.69 & 1 & $<0.0001$ \\
\hline & Univariate & $\mathrm{DC}$ & 0.0021 & 155.24 & 1 & $<0.0001$ \\
\hline & & Cte & -2.33 & 161.52 & 1 & $<0.0001$ \\
\hline & Univariate & FD & 0.103 & 127.174 & 1 & $<0.0001$ \\
\hline & & Cte & -2.58 & 165.391 & 1 & $<0.0001$ \\
\hline
\end{tabular}



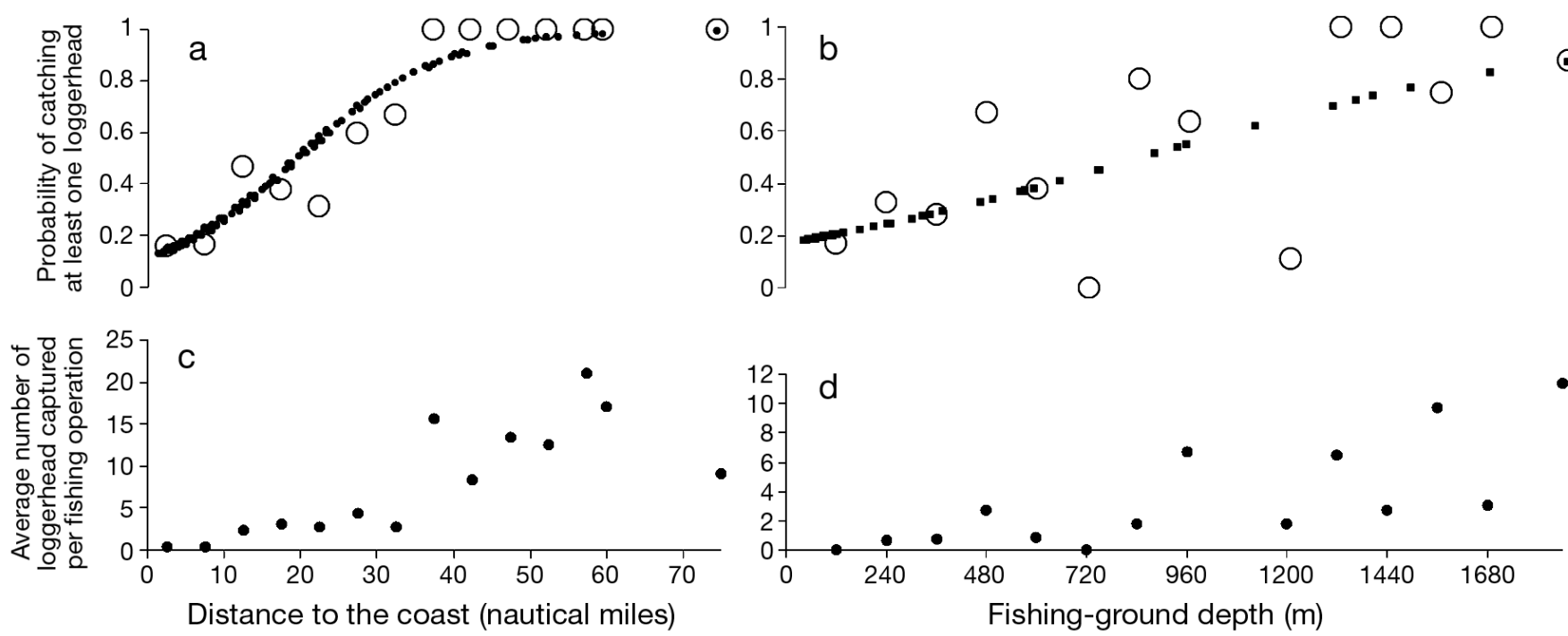

Fig. 2. Caretta caretta. By-catch per fishing operation in relation to distance to the coast and fishing-ground depth. Adjusted probability of catching at least 1 loggerhead during a fishing operation as a function of (a) distance to the coast and (b) fishingground depth. Average number of loggerheads captured per longline set within classes of (c) 5 international nautical miles $(\approx 9250 \mathrm{~m})$ of distance to the coast, and (d) $120 \mathrm{~m}$ of fishing-ground depth

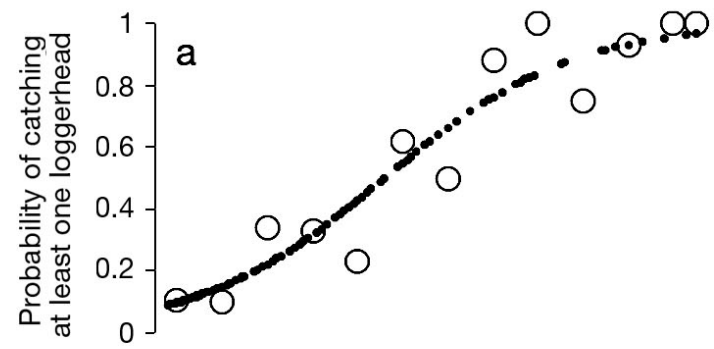

$\odot$
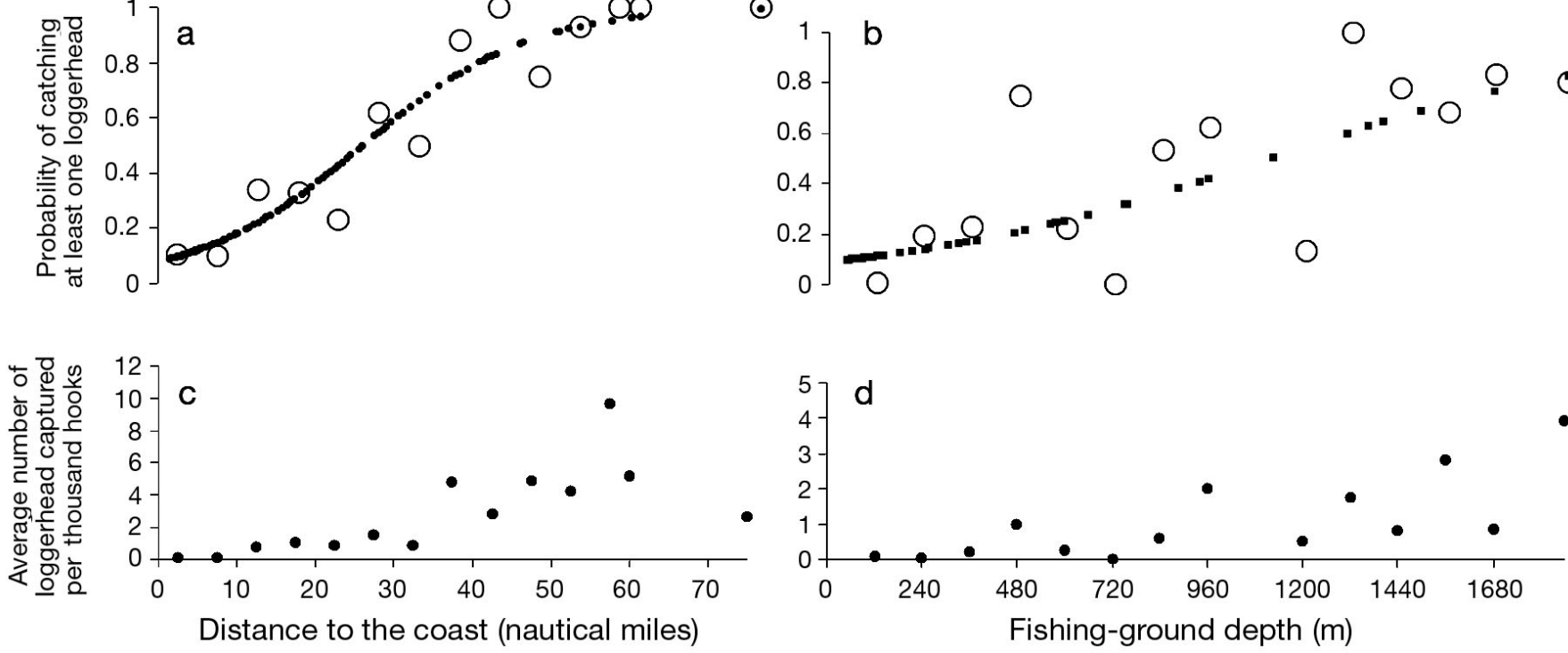

Fig. 3. Caretta caretta. By-catch per 1000 hooks in relation to distance to the coast and fishing-ground depth. Adjusted probability of catching at least 1 loggerhead in a stretch of 1000 hooks as a function of (a) distance to the coast and (b) fishing-ground depth. Average number of loggerheads captured per 1000 hooks within classes of (c) 5 international nautical miles $(\approx 9250 \mathrm{~m})$ of distance to the coast and (d) $120 \mathrm{~m}$ of fishing-ground depth

caught per fishing operation and 1 loggerhead per 1000 hooks; this value increased to 13 turtles per fishing operation and 4.48 per 1000 hooks when fishing farther than $35 \mathrm{~nm}$ from the coast. The increase in captures per fishing operation occurred even though fishing effort, in terms of the mean number of hooks per longline, decreased significantly among the 3 distance classes (Kruskal-Wallis test: $H=17.72, \mathrm{df}=2, \mathrm{p}=$ $0.00014, \mathrm{n}=179$ ).
Kendall's $\tau_{\mathrm{b}}$ correlation coefficients between ecogeographical variables and CPUE indices for loggerheads (Table 3) were high; however, we found no relationship between number of hooks per set and loggerhead by-catch, and only a weak relationship of the latter with soak time (Table 3).

We found a positive correlation between the number of loggerheads incidentally caught per longline set and fishing-ground depth only for the distance class 
between 10 and $35 \mathrm{~nm}$, and between the number of loggerheads captured per fishing operation and soak time when fishing farther than $35 \mathrm{~nm}$ from the coast (Table 4).

Distance to the coast was significantly correlated with gear retrieval time (Kendall's $\tau_{\mathrm{b}}=0.328, \mathrm{n}=126$, $\mathrm{p}<0.01$ ) and, to a lesser extent, with sea surface velocity (Kendall's $\tau_{\mathrm{b}}=-0.105, \mathrm{n}=179, \mathrm{p}<0.05$ ) and phytoplankton concentration (Kendall's $\tau_{\mathrm{b}}=-0.112, \mathrm{n}=163$, $\mathrm{p}<0.05)$.

Table 3. Significant values of Kendall's $\tau_{\mathrm{b}}$ correlation coefficient between variables observed on board. DC, distance to the coast; FD, fishing-ground depth; $\mathrm{NH}$, number of hooks; ST, soak time; SWF, number of swordfish captured per longline set; SWR, number of swordfish captured per 1000 hooks; LOF, number of loggerhead captured per longline set; LOR, number of loggerhead captured per 1000 hooks $(\mathrm{N}=179$;

$$
\mathrm{p}<0.01)
$$

\begin{tabular}{|lccccccccc|}
\hline & DC & FD & NH & ST & SWF & SWR & LOF & LOR \\
\hline DC & 1 & 0.59 & -0.22 & 0.25 & - & - & 0.47 & 0.47 \\
FD & & 1 & -0.17 & 0.28 & - & - & 0.51 & 0.51 \\
NH & & & 1 & - & 0.32 & - & - & -0.17 \\
ST & & & & 1 & 0.16 & 0.16 & 0.21 & 0.202 \\
SWF & & & & & 1 & 0.802 & - & - \\
SWR & & & & & & 1 & - & - \\
LOF & & & & & & & 1 & 0.97 \\
LOR & & & & & & & & 1 \\
\hline
\end{tabular}

Table 4. Significant values ( $p<0.01)$ of Kendall's $\tau_{b}$ correlation coefficient between explanatory variables and catch per unit effort (CPUE) indices for loggerhead in 3 classes of distance to the coast: 0 to 9.99 nautical miles (nm); 10 to $34.99 \mathrm{~nm}_{i}>35 \mathrm{~nm}$. Abbreviations as in Table 2

\begin{tabular}{lcccccc|}
\hline & DC & FD & NH & ST & LOF & LOR \\
\hline $\mathbf{0 - 9 . 9 9} \mathbf{n m}$ & & & & & & \\
DC & 1 & - & - & - & - & - \\
FD & & 1 & - & - & - & - \\
NH & & & 1 & - & - & - \\
ST & & & & 1 & - & - \\
LOF & & & & & 1 & 0.81 \\
LOR & & & & & & 1 \\
$\mathbf{1 0 - 3 4 . 9 9} \mathbf{n m}$ & & & & & & \\
DC & 1 & 0.35 & - & - & - & - \\
FD & & 1 & - & 0.28 & 0.31 & 0.31 \\
NH & & & 1 & - & - & - \\
ST & & & & 1 & - & - \\
LOF & & & & & 1 & 0.97 \\
LOR & & & & & & 1 \\
>35 nm & & & & & - & - \\
DC & 1 & - & - & - & - & - \\
FD & & 1 & -0.39 & - & - & - \\
NH & & & 1 & - & - & - \\
ST & & & & 1 & 0.5 & 0.53 \\
LOF & & & & & 1 & 0.902 \\
LOR & & & & & & 1 \\
\hline
\end{tabular}

\section{DISCUSSION}

One of our main results is the lack of correlation between loggerhead turtle by-catch and number of hooks. This put into question the use of the number of hooks as a proxy for by-catch rates and risk to loggerheads, in disagreement with Yeung (1999), Laurent et al. (2001) and Lewison et al. (2004). The probability of catching at least 1 loggerhead was related only to ecogeographical variables. The number of loggerheads captured per fishing operation was related to soak time only in the class $>35 \mathrm{~nm}$, where the probability of catching at least 1 loggerhead turtle was practically 1. The relation between soak time and by-catch has been associated with the effects of dusk and dawn, as some species may be more active at these movements (Ward et al. 2004), but in our study all fishing operations began before dusk and finished after dawn. However, a longer soak time implies that the longline set is available for a longer time during the day, which might be a more proximal cause of the increase in loggerhead turtle by-catch.

On the other hand, the number of swordfish captured was correlated with the number of hooks and soak time, which are technical variables related to fishing effort. Previous recommendations directed to diminish loggerhead by-catch (Gilman et al. 2006) focussed on technical aspects of fishing, which are resisted by fishermen due to their impact on target species yields. Our results suggest that in the Mediterranean Sea, it is not the way the longline set is conducted that affects loggerhead by-catch, but where it is conducted.

We found a remarkable relationship between loggerhead by-catch and distance to the coast and fishing-ground depth. The multivariate results indicate that both variables are important independent of one another. However, as the grouping of classes of these variables according to their average CPUE values only produced groups of contiguous classes for distance to the coast, we conclude that loggerhead by-catch is more spatially structured for this variable; therefore, distance to the coast is a better variable be use in fisheries and ecological management. While fishingground depth is a variable related to oceanic effects, distance to the coast may be related to the effect of the continent. Continental hydrographical basins provide fresh water, nutrients, and energy to nearby coastal waters, thereby affecting nutrient levels and salinity in marine areas near the coast (Mann \& Lazier 1991) as well as the distribution of seaweeds in the Mediterranean (Báez et al. 2004, 2005).

However, our results do not imply that turtles are distributed according to distance to the coast, but that captures are highly related to it. It is possible that fish- 
ing strategies vary according to distance to the coast, or that an ecological factor correlated with this distance measure affects the feeding behaviour of turtles. An anthropogenic factor related to distance to the coast is the possible interaction with trawl boats, which leave port at dawn. As the trawl boats could break the longline gear, longline fishermen tend to retrieve the gear earlier in areas near the coast. This could be the cause of the relation between distance to the coast and gear retrieval time which, in turn, could partially explain the reduction in loggerhead by-catch as a consequence of the shorter exposure of the longline during daytime. Nevertheless, distance to the coast seems to be an integrating variable, apparently incorporating depth, gear retrieval time, sea surface velocity, phytoplankton concentration, and possibly unspecified continental effects.

When the probability of catching at least 1 loggerhead was computed per longline set, the pure effect of distance to the coast was higher than that of fishing-ground depth, and the value of distance to the coast in the Wald test was also higher than that of fishing-ground depth, whereas the opposite occurred when it was computed per 1000 hooks (Table 2). The most explanatory variables were distance to the coast in the model obtained using longline set as the unit effort, and fishing-ground depth in the model obtained using the number of hooks as the unit effort. This difference may be caused by the negative correlation between fishing-ground depth and the number of hooks when fishing $>35 \mathrm{~nm}$ from the coast (Table 4), which is due to increasing the distance between hooks to allow deeper fishing. As the number of loggerheads captured was independent of the number of hooks (Table 4), this implies that when fishing occurs in deeper fishing grounds, the number of loggerheads captured per 1000 hooks increases, even when loggerhead by-catch per fishing operation does not change. This suggests that to control loggerhead by-catch, fishing operations are better unit efforts than the number of hooks, and thus the index $\mathrm{F}$ is more appropriate than $\mathrm{R}$ as the CPUE. This is in agreement with Camiñas et al. (2006), who proposed the use of $F$ rather than $R$ as a measure of CPUE for loggerhead by-catch, as they found $\mathrm{R}$ to be more sensitive to changes in boat characteristics and gear type than to overall loggerhead by-catch. However, the target species is certainly correlated with the number of hooks, and for this reason, we recommend the use of both indices, i.e. F for by-catch species and R for target species.

These results could help in the design of easy-toimplement management measures which have the potential to preserve a large number of loggerhead turtles in this area. As Spanish fishermen have a preference for fishing relatively close to the coast (to minimise running costs), the mean value of the nearest dis- tances to the coast at the beginning and end of the longline lowering (distance to the coast) could be used to regulate Spanish longline fisheries. Moreover, distance to the coast is the variable most commonly used in fishery planning, management and regulation.

Eighteen per cent of the observed fishing operations were performed $>35 \mathrm{~nm}$ from the coast, and they represented $18 \%$ of swordfish captured and $65 \%$ of loggerhead by-catch $\left(\chi^{2}\right.$ value for swordfish $=1.69, \mathrm{df}=1$, non-significant; $\chi^{2}$ value for loggerhead by-catch $=$ 956.84, $\mathrm{df}=1, \mathrm{p}<0.0001$ ). For this reason, limiting the surface longline fishing activity to within $35 \mathrm{~nm}$ of the coast during summertime could reduce loggerhead turtle by-catch substantially with little resistance from fishermen and without affecting swordfish captures, since the swordfish catch is not correlated with distance to the coast. More studies are needed to assess the sustainability of the swordfish stock at different distances from the coast.

In other areas, the critical distance to the coast may differ due to the existence of other competing fisheries, or to different oceanographic and ecological features. Our recommendation could be useful in the western Mediterranean Sea and possibly in the eastern Mediterranean Sea, but is probably not applicable to the Atlantic or Pacific Oceans, where the fishing grounds are located much farther from the coast. However, our conclusion that these ecogeographical variables are more important than technical variables in explaining sea turtle by-catch could also be valid elsewhere. Ecological variables have been neglected in previous studies of loggerhead by-catch (e.g. Swimmer et al. 2005, Watson et al. 2005, Gilman et al. 2006). For pelagic longline fisheries in the oceans, variables such as fishing-ground depth, distance to upwellings, or distance to the surface currents should be evaluated.

Acknowledgements. This study was supported by the IEO and the European Union projects SWOMED (Swordfish fisheries in the Mediterranean Sea) and Panlandalife (Conservation of cetaceans and sea turtles in Murcia and Andalucía, LIFE02NAT E/8610), and by the Consejería de Innovación, Ciencia y Empresa of the Junta de Andalucía (research project no. P05-RNM-00935).

\section{LITERATURE CITED}

Báez JC, Real R, Vargas JM, Flores-Moya A (2004) A biogeographical analysis of the genera Audoinella (Rhodophyta), Cystoseira (Phaeophyceae) and Cladophora (Chloropyta) in the western Mediterranean Sea and Adriatic Sea. Phycologia 43:404-415

Báez JC, Olivero J, Real R, Vargas JM, Flores-Moya A (2005) An analysis of the geographical variation in species richness in the genera Audouinella (Rhodophyta), Cystoseira (Phaeophyceae) and Cladophora (Chlorophyta), in the western Mediterranean Sea. Bot Mar 48:30-37 
Báez JC, Camiñas JA, Rueda L (2006) Accidental fishing capture of marine turtles in South Spain. Mar Turtle Newsl 111:11-12

Camiñas JA, Báez JC, Valeiras X, Real R (2006) Differential loggerhead by-catch and direct mortality in surface longline according to boat strata and gear type. Sci Mar 70: 661-665

Carranza A, Domingo A, Estrades A (2006) Pelagic longlines: a threat to sea turtles in the Equatorial Eastern Atlantic. Biol Conserv 131:52-57

Chaloupka M, Parker D, Balazs D (2004) Modelling postrelease mortality of loggerhead sea turtles exposed to the Hawaii-based pelagic longline fishery. Mar Ecol Prog Ser 280:285-293

Cheng JJ, Chen TH (1997) The incidental capture of five species of sea turtles by coastal setnet fisheries in the eastern waters of Taiwan. Biol Conserv 82:235-239

FAO (2004) Expert consultation on interactions between sea turtles and fisheries within an ecosystem context. Rome, Italy, 9-12 March 2004. FAO Fish Rep No.738

Gilman E, Zollet E, Beverly S, Nakano H, Davis K, Shiode D, Dalzell P, Kinan I (2006) Reducing sea turtle by-catch in pelagic longline fisheries. Fish Fish 7:2-23

Hirzel AH, Hausser J, Chessel D, Perrin N (2002) Ecologicalniche factor analysis: How to compute habitat-suitability maps without absence data? Ecology 83:2027-2036

Hosmer DW, Lemeshow S (2000) Applied logistic regression, 2nd edn. John Wiley \& Sons, New York

IUCN (2004) 2004 IUCN red list of threatened species. International Union for Conservation of Nature and Natural Resources, Species Survival Commission, Red List Programme, Cambridge, UK and Gland, Switzerland. Available at: www.iucnredlist.org/search/search-expert.php

Julian F, Beeson M (1998) Estimates of marine mammal, turtle and seabird mortality for two California gillnet fisheries 1990-1995. Fish Bull 96:271-284

Laurent L, Camiñas JA, Casale P, Deflorio M and 5 others (2001) Assessing marine turtle bycatch in European drifting longline and trawl fisheries for identifying

Editorial responsibility: Otto Kinne (Editor-in-Chief), Oldendorf/Luhe, Germany fishing regulations. Project-EC-DG Fisheries 98-008. Joint project of BIOINSIGHT, IEO, IMBC, STPS and University of Bari. Villeurbanne. Available at www.sea turtle.org/documents/EMTP-FINAL-REPORT.pdf

Lewison RL, Freeman SA, Crowder LB (2004) Quantifying the effects of fisheries on threatened species: the impact of pelagic longlines on loggerhead and leatherback sea turtles. Ecol Lett 7:221-231

Mann KH, Lazier JRN (1991) Dynamics of marine ecosystems. Biological-Physical interactions in the oceans. Blackwell Scientific Publications, New York

Murray KT (2004) Magnitude and distribution of sea turtle bycatch in the sea scallop (Placopecten magellanicus) dredge fishery in two areas of the northwestern Atlantic Ocean, 2001-2002. Fish Bull 102:671-681

Robins JB (1995) Estimated catch and mortality of sea turtles from the east coast otter trawl fishery of Queensland, Australia. Biol Conserv 74:157-167

Silvani L, Gazo M, Aguilar A (1999) Spanish driftnet fishing and incidental catches in the western Mediterranean. Biol Conserv 90:79-85

Swimmer Y, Arauz R, Higgins B, McNaughton L, McCracken M, Ballestero J, Brill R (2005) Food color and marine turtle feeding behavior: Can blue bait reduce turtle bycatch in commercial fisheries? Mar Ecol Prog Ser 295:273-278

Ward P, Myers RA, Blanchard W (2004) Fish lost at sea: the effect of soak time on pelagic longline catches. Fish Bull 102:179-195

Watson JW, Epperly SP, Shah AK, Foster DG (2005) Fishing methods to reduce sea turtle mortality associated with pelagic longlines. Can J Fish Aquat Sci 62:965-981

Witzell WN (1999) Distribution and relative abundance of sea turtles caught incidentally by the U.S. pelagic longline fleet in the western North Atlantic Ocean, 1992-1995. Fish Bull 97:200-211

Yeung C (1999) Estimates of marine mammal and marine turtle bycatch by the U.S. Atlantic pelagic longline fleet in 1998. NOAA Tech Mem NMFS-SEFSC-430. Available at: www.sefsc.noaa.gov/PDFdocs/Yeung1999.pdf

Submitted: June 9, 2006; Accepted: November 1, 2006 Proofs received from author(s): May 4, 2007 